\title{
Endobronchial Actinomycosis Associated with a Foreign Body-Successful Short-term Treatment with Antibiotics-
}

\author{
Kanako Maki ${ }^{1}$, Naofumi Shinagawa ${ }^{1}$, Yasuyuki Nasuhara ${ }^{1}$, Satoshi Oizumi ${ }^{1}$, \\ Hiromitsu Domen ${ }^{2}$, Hironori Haga ${ }^{2}$ and Masaharu Nishimura ${ }^{1}$
}

\begin{abstract}
Primary endobronchial actinomycosis is a very rare condition. We report herein the case of a healthy 66year-old woman who presented with right lower lobe endobronchial actinomycosis associated with aspiration of a foreign body, which was presumed to be a fish bone swallowed 28 months previously. The patient achieved complete clinical and radiological recovery after removal of the foreign body and 1-month antibiotic therapy of oral amoxycillin. Our experience in the management of this patient should help clinicians to realize the importance of bronchoscopic investigation and the management of this rare but treatable condition.
\end{abstract}

Key words: actinomycosis, foreign body, antibiotics

(Inter Med 49: 1293-1296, 2010)

(DOI: 10.2169/internalmedicine.49.3475)

\begin{abstract}
Introduction
Actinomycosis is a chronic suppurative infection due to a group of Actinomyces, gram-positive anaerobic organisms belonging to the resident flora of the oropharynx, gastrointestinal tract, and woman genitalia. Actinomyces israelii is the main representative pathogen in human infection. Twenty percent of cases of actinomycosis occur in the thorax (1). Primary endobronchial actinomycosis is rare and very uncommon in association with foreign body aspiration (2), and can closely mimic endobronchial carcinoma (3-6). Presentations of thoracic actinomycosis in recent years have tended to be milder than in earlier reports, due to recent improvements in oral hygiene and the ready availability of antibiotics $(1,7)$. This suggests that the traditional recommendation of long-term antibiotic therapy could be reevaluated. Several recent investigators have treated thoracic actinomycosis with a relatively brief course of therapy (8-10).

We present herein a case of endobronchial actinomycosis associated with a foreign body and discuss the possibility of short-term antibiotic treatment for this rare disease.
\end{abstract}

Case Report

A 64-year-old immunocompetent woman presented with a 7-month history of cough and productive purulent sputum. Chest computed tomography (CT) showed consolidation and peribronchial small nodules in the right lower lobe. She was referred to our unit for further investigation and management in August 2008. No other symptoms associated with respiratory infection were evident, such as hemoptysis, dyspnea, or fever. Although she had a 12 pack-year history of smoking, she had not smoked for the last 22 years. There was no previous history of cerebrovascular events, swallowing difficulties, diabetes mellitus, alcoholism, or dental problems. However, in April 2006, she swallowed a fish bone and went to an otolaryngologist and an internist. Laryngoscopy and endoscopy of the upper gastrointestinal tract could not find the bone, but laryngeal discomfort disappeared spontaneously and no further examination was performed.

Physical examination on admission showed a body temperature of $36.7^{\circ} \mathrm{C}$, and percutaneous oxygen saturation 97\%. Upon auscultation, inspiratory coarse crackles were audible in the right lower lung. Examination of other sys-

${ }^{1}$ First Department of Medicine, Hokkaido University School of Medicine, Sapporo and ${ }^{2}$ Department of Surgical Pathology, Hokkaido University Hospital, Sapporo

Received for publication February 3, 2010; Accepted for publication March 23, 2010

Correspondence to Dr. Kanako Maki, kana5@med.hokudai.ac.jp 


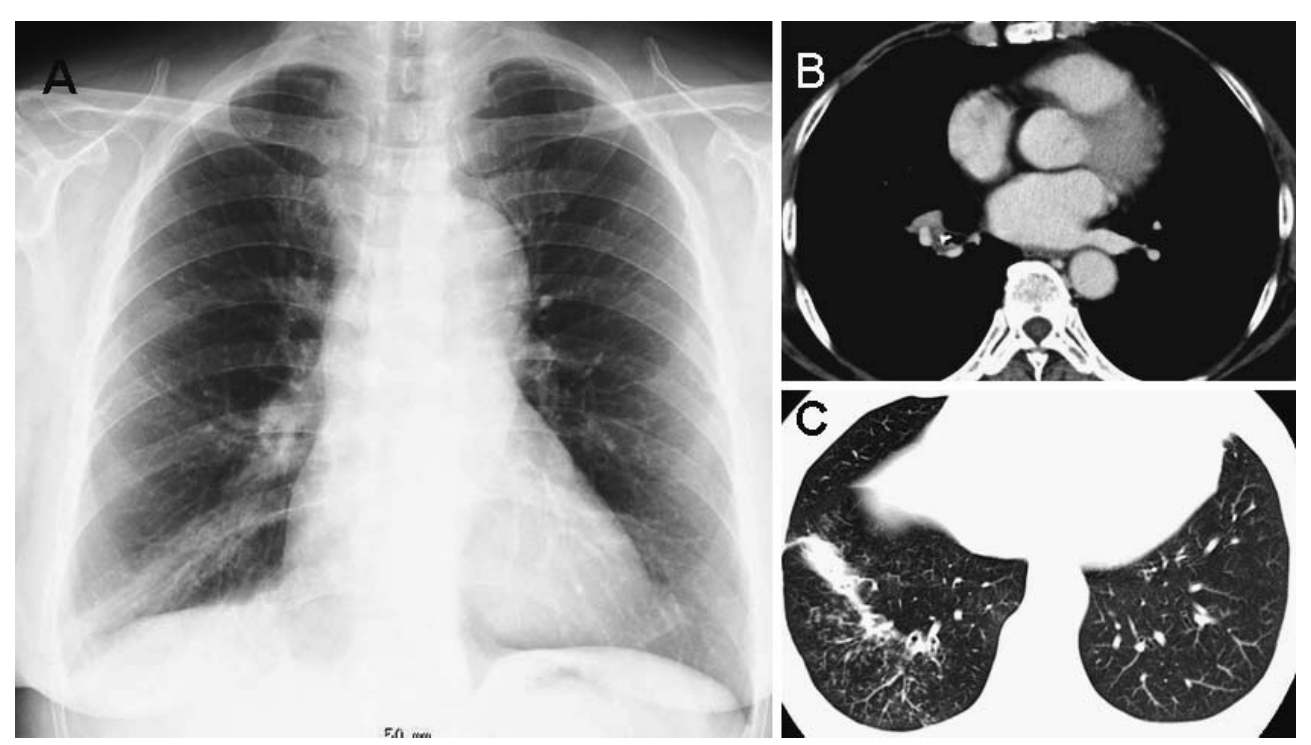

Figure 1. (A) Chest radiography showing increased opacity in the right lower lung. Chest CT shows an intraluminal calcified structure within the basal segmental bronchus (B) and consolidation and peribronchial small nodules in the right lower lobe (C).

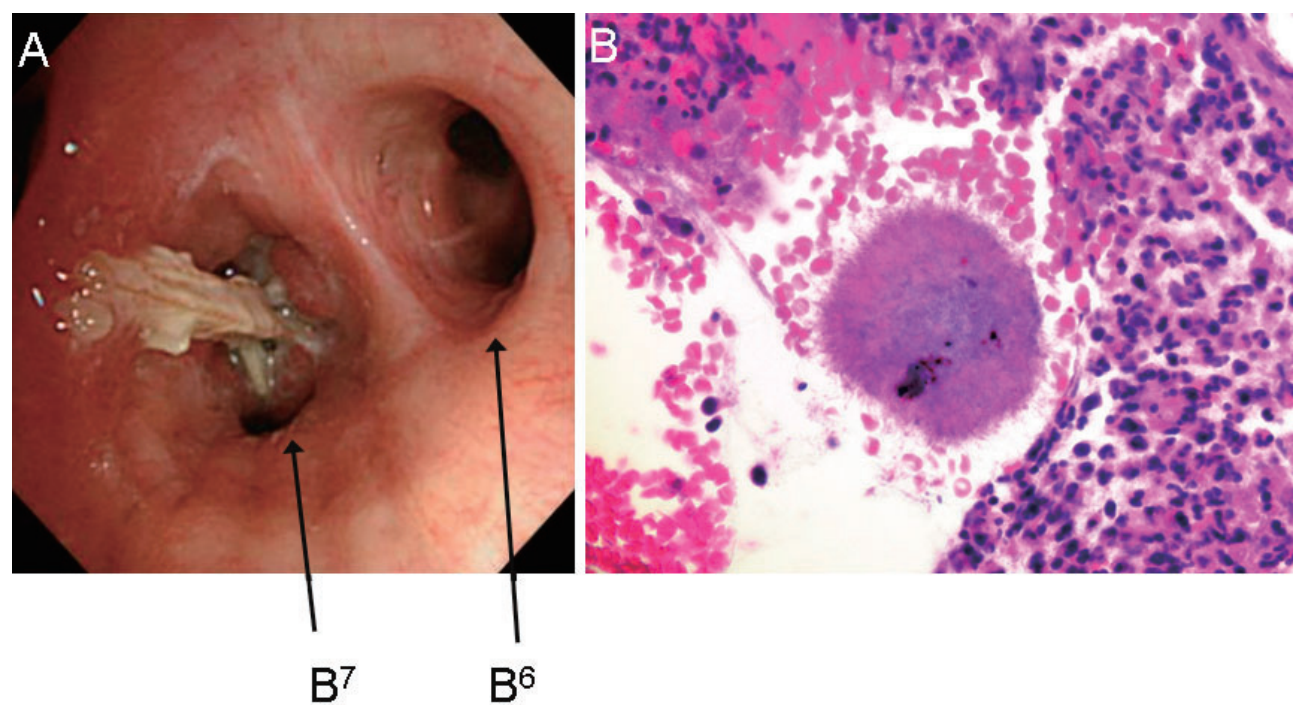

Figure 2. (A) Bronchoscopy showing the right basal segmental bronchi obstructed by a foreign body and granulation tissue. (B) Gram staining of biopsy specimens revealing sulfur granules surrounded by infiltration of neutrophils.

tems including dental hygiene was unremarkable. Laboratory examination showed a white blood cell count of $5,900 / \mu \mathrm{L}$ and an erythrocyte sedimentation rate of $14 \mathrm{~mm} / \mathrm{h}$. Creactive protein level was $0.3 \mathrm{mg} / \mathrm{dL}$. Cytologic examination of sputum demonstrated numerous neutrophils and a few squamous cells, but no evidence of malignant cells. Bacteriologic examination of sputum showed no evidence of mycobacterial tuberculosis or fungal infection. Chest radiography revealed right lower lobe infiltrate (Fig. 1A). Chest CT showed an intraluminal calcified structure, compatible with a fish bone, embedded within the lumen of the basal segmental bronchus (Fig. 1B), lymph adenopathy of the paratracheal region, and consolidation and peribronchial small nodules in the right lower lobe (Fig. 1C).
Flexible bronchoscopy performed under local anesthesia showed obstruction of the lumen of the basal segmental bronchus by a fragment of a foreign body and granulation tissue (Fig. 2A). A large amount of green-colored sputum was aspirated from the right basal bronchus. Due to cough and bleeding, removal of the foreign body under local anesthesia was difficult. After 12 days, bronchoscopy was performed again under general anesthesia. The foreign body surrounded by granulation tissue was removed in several pieces using biopsy forceps. After removal of the foreign body, chest CT revealed that obstruction of the right basal bronchus was relieved and peribronchial small nodules in the right lower lobe had disappeared, with the exception of consolidation and a small fragment of bone in the anterior 


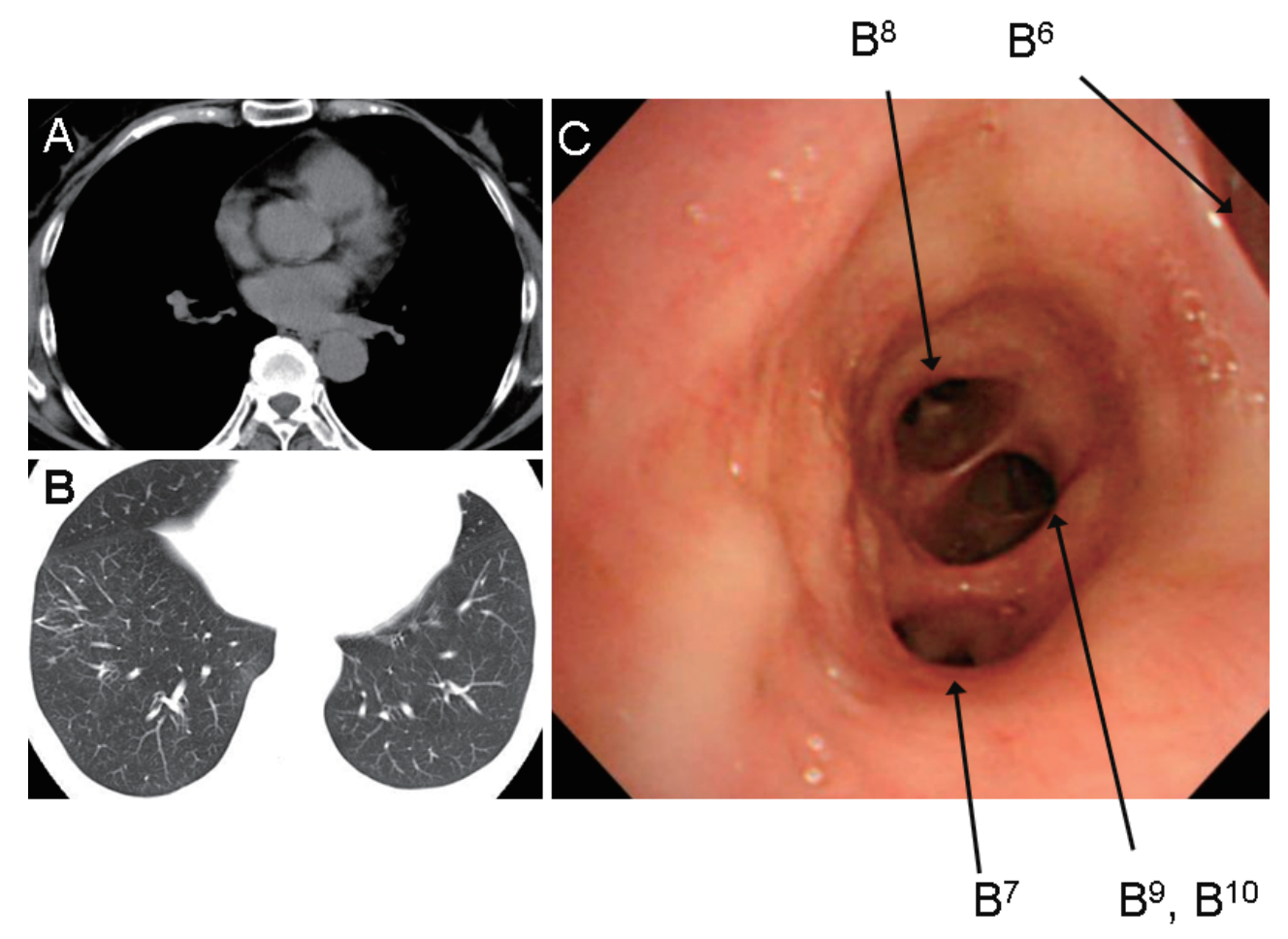

Figure 3. Chest CT showing no foreign body (A) or infiltration in the right lower lobe (B). Bronchoscopy likewise shows no foreign body or granulation tissue (C).

basilar segment of the right lower lobe.

Histologically, biopsy specimens of the foreign body and granulation tissue revealed fragments of bone surrounded by acute inflammatory exudates and Gram-positive sulfur granules (colonies of organisms forming an amorphous center surrounded by a rosette of clubbed filaments) (Fig. 2B). The diagnosis was endobronchial actinomycosis. Two weeks after removal of the foreign body, the patient suffered from slight fever and fatigue for 3 days. Laboratory examination showed a white blood cell count of $8,700 / \mu \mathrm{L}$, and C-reactive protein level was $4.80 \mathrm{mg} / \mathrm{dL}$. Chest radiography showed infiltration in the right lower lung. The patient was administered oral $2 \mathrm{~g} /$ day of amoxicillin and oral $200 \mathrm{mg} /$ day of minocycline. Minocycline was suspended after 3 days because of dizziness. Fever disappeared in 2 days. C-reactive protein level normalized and infiltration on chest radiography decreased within 1 week. Oral antibiotics were continued for 1 month after infiltration on chest radiography diminished. As of 40 days after starting pharmacotherapy, chest CT showed no pieces of the foreign body or infiltration in the right lower lobe (Fig. 3A, B). Bronchoscopy showed neither foreign body nor granulation tissue (Fig. 3C). The patient has remained well on follow-up for 14 months.

\section{Discussion}

Bronchial involvement is a rare form of thoracic actinomycosis that has been reported to be associated with foreign bodies. The first report of foreign body-induced endobron- chial actinomycosis was the case of a Spanish patient in 1991, when a chicken bone was aspirated (11). Chouabe et al reviewed 11 cases of endobronchial actinomycosis associated with foreign bodies (4). The main symptoms include cough, fever, expectoration of yellow pus, chest pain, and weight loss. Chest CT shows a thickened bronchial wall, dense pulmonary alveolar opacity, atelectasis, pleural effusion, bronchiectasis, lymphadenopathy, or a radiopaque foreign body. Actinomyces tend to colonize and subsequently invade the tissue surrounding the foreign body. Obstructive endoluminal masses have been found on bronchoscopy, but the actual foreign bodies are not detected easily in some cases $(3,4)$. Kim et al reported a case of foreign bodyinduced endobronchial actinomycosis. After treatment with penicillin, follow-up bronchoscopy revealed an aspirated fish bone at the site of infection (5). Endobronchial actinomycosis may mimic endobronchial carcinoma, benign tumor including endobronchial lipoma, and tuberculosis $(1-4,8,9,12,13)$. In the present case, we were able to predict the existence of a foreign body due to the known history of aspiration and available chest CT findings. Two weeks after removal of the foreign body, the patient suffered again from pneumonia, which was presumed to be worsening of actinomycosis, because pathological findings had demonstrated numerous Actinomyces species, and antibiotic therapy had not been started at this point.

The optimal duration of total antibiotic therapy for thoracic actinomycosis, as well as the optimal duration of intravenous antibiotic therapy, has not been thoroughly evaluated, although a total duration of 6-12 months is generally 
recommended $(8,10,12)$. Several investigators have reported relatively brief courses of antibiotic therapy being successful in cases of thoracic actinomycosis $(2,8,10)$. Umeki et al reported successful resolution of foreign bodyinduced endobronchial actinomycosis using 2 weeks of intravenous Penicillin $G$ with bronchoscopic removal of the foreign body (14). Since most of the foreign body could be removed by bronchoscope in the present case, oral antibiotics were withdrawn after only 1 month of therapy, without relapse during a 14-month observation period. To the best of our knowledge, this represents the shortest duration of successful oral antibiotic therapy for endobronchial actinomyco- sis associated with a foreign body. The excellent radiological and clinical responses to antibiotic treatment were probably the result of extraction of the foreign body.

In conclusion, foreign body-induced endobronchial actinomycosis is very rare, but is readily treatable. Diagnosis by bronchial biopsy alleviates the patient need for a major surgical procedure and leads to complete cure by antibiotic treatment. The traditional recommendation of long-term antibiotic therapy is not always necessary for patients with endobronchial actinomycosis when the causative foreign body can be removed bronchoscopically.

\section{References}

1. Hsieh MJ, Liu HP, Chang JP, Chang JP, Chang CH. Thoracic actinomycosis. Chest 104: 366-370, 1993.

2. Dalhoff K, Wallner S, Finck C, Gatermann S, Weissmann KJ. Endobronchial actinomycosis. Eur Respir J 7: 1189-1191, 1994.

3. Ariel I, Breuer R, Kamal NS, Ben-Dov I, Mogle P, Rosenmann E. Endobronchial actinomycosis simulating bronchogenic carcinoma: Diagnosis by bronchial biopsy. Chest 99: 493-495, 1991.

4. Chouabe S, Perdu D, Deslee G, Milosevic D, Marque E, Lebargy F. Endobronchial actinomycosis associated with foreign body. Four cases and a review of the literature. Chest 121: 2069-2072, 2002.

5. Kim YS, Suh JH, Kwak SM, et al. Foreign body-induced actinomycosis mimicking bronchogenic carcinoma. Korean J Intern Med 17: 207-210, 2002.

6. Ho JCM, Ooi GC, Lam YK, Lam B, Cheung TF, Tsang KW. Endobronchial actinomycosis associated with a foreign body. Respirology 5: 293-296, 2000.

7. Boe DM, Groshong SD, Canham M. A 59-year-old man with chronic cough. Chest 134: 876-882, 2008.

8. Choi JC, Koh WJ, Kim TS, et al. Optimal duration of IV and oral antibiotics in the treatment of thoracic actinomycosis. Chest 128: 2211-2217, 2005.

9. Sudhakar SS, Ross JJ. Short-term treatment of actinomycosis. Clin Infect Dis 38: 444-447, 2004.

10. Yildiz O, Doganay M. Actinomycosis and Nocardia pulmonary infection. Curr Opin Pulm Med 12: 228-234, 2006.

11. Julia G, Rodriguez de Castro F, Caminero J, Rey A, Cabrera P. Endobronchial actinomycosis associated with a foreign body. Respiration 58: 229-230, 1991.

12. Mabeza GF, Macfarlane J. Pulmonary actinomycosis. Eur Respir J 21: 545-551, 2003.

13. Kurai M, Yamanda T, Koyama S, Tunoda T, Gono H. A case of hemoptysis caused by vegetable foreign body (cryptomeria) and actinomycosis. Nihon Kokyuki Gakkai Zasshi 40: 915-918, 2002 (in Japanese, Abstract in English).

14. Umeki S, Nakajima M, Tsukiyama K, Okimoto N, Yagi S, Soejima R. Foreign body-induced bronchial actiomycosis with severe stenosis that must be distinguished from lung cancer. Nihon Kyoubu Shikkan Gakkai Zasshi 28: 481-486, 1990 (in Japanese, Abstract in English).

(C) 2010 The Japanese Society of Internal Medicine http://www.naika.or.jp/imindex.html 